INDEPENDENT JOURNAL OF MANAGEMENT \& PRODUCTION (IJM\&P)

http://www.ijmp.jor.br

v. 12, n. 8, November-December 2021

ISSN: 2236-269X

DOI: 10.14807/ijmp.v12i8.1491

\title{
COVID-19: A DECISION-MAKING APPROACH FOR EVALUATING THE ECONOMIC SECTORS OF INDIA DURING PANDEMIC
}

\author{
Srikant Gupta \\ Department of Operations Management and Decision Sciences \\ Jaipuria Institute of Management, India \\ E-mail: operation.srikant@hotmail.com
}

Submission: $11 / 16 / 2020$

Revision: $12 / 1 / 2020$

Accept: 12/17/2020

\section{ABSTRACT}

The advent of COVID-19 has escalated into a pandemic and, as a result of infected cases and human fatalities, it tends to rise day by day across the globe. This also ignited concerns of a looming fiscal slump and recession on the different economic sectors as well. The effect of this pandemic is much more significant in developing countries like India due to the already declining growth rate, inadequate health services, and a growing population residing in severe poverty. This paper attempts to understand the impact of COVID-19 pandemic on the Indian economic sectors by employing a hierarchical approach, based on multi-criteria analysis to understand the impact on primary, secondary, tertiary and quaternary sectors by concerning the political, economic, socio-cultural and technology consequences of COVID-19. A process-based multi-criteria hierarchical approach has been used to determine the effect of the same and has been prioritized in the sequential sequence.

Keywords: COVID-19; Pandemic; Economic Sectors; AHP; TOPSIS 
DOI: 10.14807/ijmp.v12i8.1491

\section{INTRODUCTION}

India is one of the most affected countries from the COVID-19 outbreak, with more than 20 lakh cases. The government implemented nationwide lockdown in the country to reduce the spread of coronavirus. The country lockdown began in late March and was subsequently extended several times. The Indian economy has been severely impacted by the lethal virus shocks that have caused businesses to urge their workers to operate from home to prevent contracting coronavirus.

Today, nearly all small and medium-sized companies are out of operation as a consequence of the lockdown, are unwilling to compensate their workers, and others do not have the financial means to reopen their businesses. Regular wage employees, private staff, drivers, hawkers, store owners and thousands of related employees have lost their livelihood. All the businesses were severely impacted, including movies, tourism, food franchises were shut down, causing a crisis scenario all over as the major streets and markets started to look empty.

The global economist believes that, if an early solution for COVID-19 is not found, the future would be awful to forecast. The first referred to the confusion concerning the potential direction of the pandemic. None of us can say with any certainty when the pandemic cases will peak, or how easily the slope will collapse after it has peaked. Some of the recent articles related with the impact of COVID-19 on the India economy are, Sharma et al. (2020a) demonstrated the influence of the COVID-19 outbreak on the Indian economy by utilizing empirical research, focused on a perception survey, to identify the view of fifteen industry experts on the socio-economic effects of COVID-19.

Gopalan and Misra (2020) gave heed to the rippling impact of the lockdown on the economic crisis and thereby effect on housing, education and other sectors. Sengupta and Jha (2020) explored the essence and extent of current social programs intended to safeguard the marginalized community and to reduce dislocation, inequality and poverty during the pandemic period and even in the future amid shifting political systems and an evolving economic environment.

Dev and Sengupta (2020) identified the condition of the Indian economic condition in the Covid-19 era, assessed the possible effect of the disruption on different businesses, and also evaluated the policies implemented by the government to enhance the economic sectors. Buheji et al. (2020) studied the socio-economic effect of the pandemic to evaluate whether it 
DOI: 10.14807/ijmp.v12i8.1491

poses different challenges to the marginalized and proposed solutions that reduce the pandemic effects on the livelihoods and socio-economic practices of the poor people.

Verma et al. (2020) examined the effect of COVID-19 on the economy of India, culture, politics and strategy to geopolitics. Reardon et al. (2020) discussed the instability of India's food supply chains occurred due to COVID-19 and also stressed the government's to mitigate supply chain instability and repercussions from lockdowns as to improve the economy. Sharma et al. (2020b) recognized the complexities of the Covid-19 pandemic in South Asia; and examined the political and practical approaches of policy leaders and health practitioners to tackle the pandemic in South Asia, respectively.

Deshmukh and Haleem (2020) clearly illustrated numerous factors and corresponding recommendations for strengthening India's manufacturing productivity during the outbreak of COVID-19. Balajee et al. (2020) determined the relationship between fiscal expenditure and COVID-19 cases, policy rigor and economic and financial influences on the Gross Domestic Product of India.

They also indicated that the government should also view this situation as an incentive to rationalize current policies and enhance the computational effects of COVID-19, as well as avoid potential debt burden. Dev (2020) discussed the effect of COVID-19 on cultivation, food availability and livelihood opportunities in India.

\section{METHODOLOGY}

India continued to remain the fastest growing major economy in the world in 20182019 (Ministry of Statistics and Program Implementation, Government of India). The April 2019 Report of the World Economic Outlook of International Monetary Fund projected India's GDP to grow even higher, at 7.3 percent in 2019. Based on the literature, this paper aims to investigate the impact of pandemic on the different economic sectors of India and also analyzed which economic sectors of the India affected the most during this COVID-19 pandemic.

To fulfil the objective of this paper, the sample was selected from online databases and questionnaires were sent to 600 academicians, industrial experts with the use of purposive sampling. The online mailing, telephonic interviews, and two follow-ups fetch 450 usable responses. The time period of data collection was April - July 2020. The illustrated figure of economic sectors and their main criteria for evaluation is given in Figure (2) shows the proposed research model. 
DOI: 10.14807/ijmp.v12i8.1491

The first objective of the study is to identify the attributes for successful implementation of the economic sectors. For first objective, we have used two approaches: review of the existing literature and discussion with industrial experts and academicians. In the first approach, current literature was reviewed in the field of agile manufacturing and was shortlisted by the authors. Further, after several rounds of brainstorming and discussion, the attributes were identified and analyzed. In second approach, industrial experts and academicians were invited to seek their guidance to finalize attributes to be considered for this study. Experts were selected very carefully to ensure valid results for the research (Sharma et al. 2020a).

Once the objective was explained, discussions were held with the experts and attributes were finalized. Finally, sixteen attributes were discovered from literature support and guidance of experts and academicians. The second aim of this study is to prioritize attribute and subattributes that can be used for the evaluation of the different economic sectors of India. The present study employed an integrated Analytic Hierarchy Process (AHP) - The Technique for Order of Preference by Similarity to Ideal Solution (TOPSIS) approach for prioritizing the attributes and sub-attributes for successful implementation of the study. A questionnaire was developed to collect the data from the academicians and industry experts. The layout of the questionnaire was as follows:

(1) Introduction to economy and economic sectors

(2) Description of attributes and sub-attributes

(3) Guidelines on how to fill in the questionnaire tables

(4) Pairwise comparison matrix of the factors.

The data analysis part was divided into two sections. The first section comprised of application of AHP to assign weights to various attributes (section 2.1). The second section involved application of TOPSIS to assign ranks to different attributes as per closeness index value (section 2.2). In the current study, AHP is used to calculate the weightages, which will serve as a primary input to TOPSIS analysis.

\subsection{Determination of criteria weights}

AHP procedure (Saaty, 1989; Wu et al., 2009) for determining the weightage of the economic factors is described below:

- Step i) Construct pair-wise comparisons; the next step after determining the weight of each attribute is to figure out the relative significance of one alternative over another. 
DOI: 10.14807/ijmp.v12i8.1491

- Step ii) Sum up the values of each column obtained from the pair-wise comparison.

- Step iii) In order to get the matrix normalized, divide each element of the column of pair-wise matrix with its corresponding sum.

- Step iv) The next step is, to sum up, all the elements of each row obtained by using step (iii) and dividing it by the number of elements in each row. The outcome indicates each alternative the total priority rating.

- Step v) The last step is to calculate the priority vectors of the alternatives obtained by multiplying the pair-wise comparisons of the alternatives matrix and the criteria weight.

\section{- Step vi) Consistency Checking}

Comparisons are assumed to be reasonably compatible in the decision matrix if the resulting "Consistency Ratio (CR)" is less than 10 percent. A "Consistency Index (CI)" is specified for the measurement of the CR coefficient, which is determined as follows:

$$
C I=\frac{\lambda_{\max }-n}{n-1}
$$

Where $\lambda_{\max }$ is the maximum eigenvalue of the matrix for a pair comparison However, the CR is determined by dividing the CI value by the "Random Consistency Index (RCI)", as shown in equation (2)

$$
C R=\frac{C I}{R C I}
$$

Table 1: RCI Value

$\begin{array}{ccccccccccc}\mathbf{n} & \mathbf{1} & \mathbf{2} & \mathbf{3} & \mathbf{4} & \mathbf{5} & \mathbf{6} & \mathbf{7} & \mathbf{8} & \mathbf{9} & \mathbf{1 0} \\ \mathbf{R C I} & 0 & 0 & 0.52 & 0.89 & 1.11 & 1.25 & 1.35 & 1.4 & 1.45 & 1.49\end{array}$

When the CR value is smaller than or equivalent to 10 percent, data is considered to be accurate, however, if it is greater than 10 percent, it is not reliable.

\subsection{Determination of Attributes}

TOPSIS procedure (Hwang et al., 1993; Dwiedi et al., 2018) for determining the rank of the attributes is described below:

- Step i) Use the equation (3) to construct the normalized decision matrix

$$
R_{i j}=\frac{S_{i j}}{\sqrt{\sum_{i=1}^{m} S_{i j}^{2}}}, i=1,2,3, \ldots, m \text { and } j=1,2,3, \ldots, n
$$


DOI: $10.14807 /$ ijmp.v12i8.1491

- Step ii) Calculate the weighted normalized decision matrix $\left(V_{i j}\right)$ after obtaining the normalized matrix, by using equation (4)

$$
V_{i j}=R_{i j}^{*} w_{j}
$$

- Step iii) Determine the ideal solution of each of the attributes i.e, assume that $V^{+}$be the positive ideal solution of the attribute's and $V^{-}$be the negative ideal solution of the attribute's.

$$
\begin{aligned}
& V_{i}^{+}=\left\{\left(\max \left(V_{i j}\right) \mid j \in J_{-}\right),\left(\min \left(V_{i j}\right) \mid j \in J\right)\right\} \\
& V_{i}^{-}=\left\{\left(\min \left(V_{i j}\right) \mid j \in J_{-}\right),\left(\max \left(V_{i j}\right) \mid j \in J\right)\right\}
\end{aligned}
$$

Where, $J_{+}$and $J_{-}$have a favourable and detrimental effect correlated with the attribute’s.

- Step iv) Compute the equidistant measure from each of the positive and negative ideal solutions, i.e.,

Use the equation (6) to determine the equidistant of each alternative from the positive ideal solution:

$$
d_{i}^{+}=\sqrt{\sum_{j=1}^{n}\left(V_{i j}-V_{j}^{+}\right)^{2}}
$$

Use the equation (8) to determine the equidistant of each alternative from the negative ideal solution:

$$
d_{i}^{-}=\sqrt{\sum_{j=1}^{n}\left(V_{i j}-V_{j}^{-}\right)^{2}}
$$

- Step v) Use the equation (9) to determine relative proximity to the ideal solution and rank them.

$$
R_{i}^{*}=\frac{d_{i}^{-}}{d_{i}^{+}+d_{i}^{-}}, 0 \leq R_{i}^{*} \leq 1
$$

Note that, the higher the relative proximity value, the higher the rating order and hence the better the alternative results. 
DOI: 10.14807/ijmp.v12i8.1491

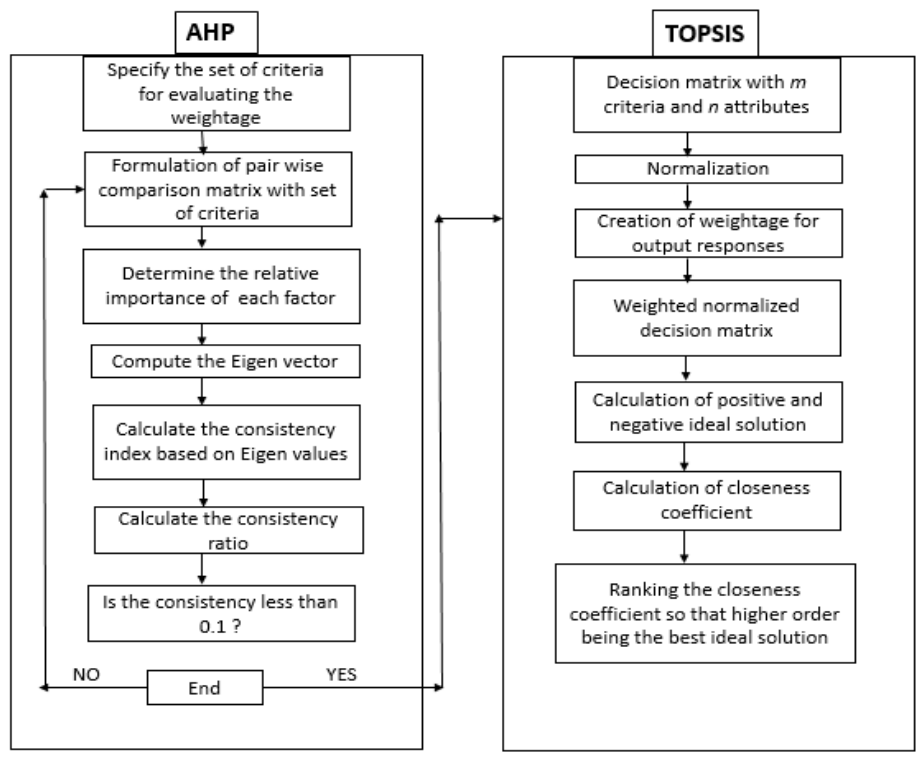

Figure 1: Flowchart for AHP-TOPSIS method (Babu and Venkataramaiah 2015)

\section{APPLICATION OF THE PROPOSED FRAMEWORK}

In the first step of the multi-criteria decision-making process, assessment criteria and attributes should be defined, and the organizational framework of the problem should be formed. In this regard, in the first instance, experts from various fields, such as academicians, businessmen, and entrepreneurs, were surveyed to decide the main and sub-criteria relevant for the evaluation of the economic sectors. They were asked in the survey to rank between 1 and 9 the main criteria and sub-criteria in order of priority, and the hierarchy was created or selected based on the overall score. The proposed framework has been summarized in the Figure 2.

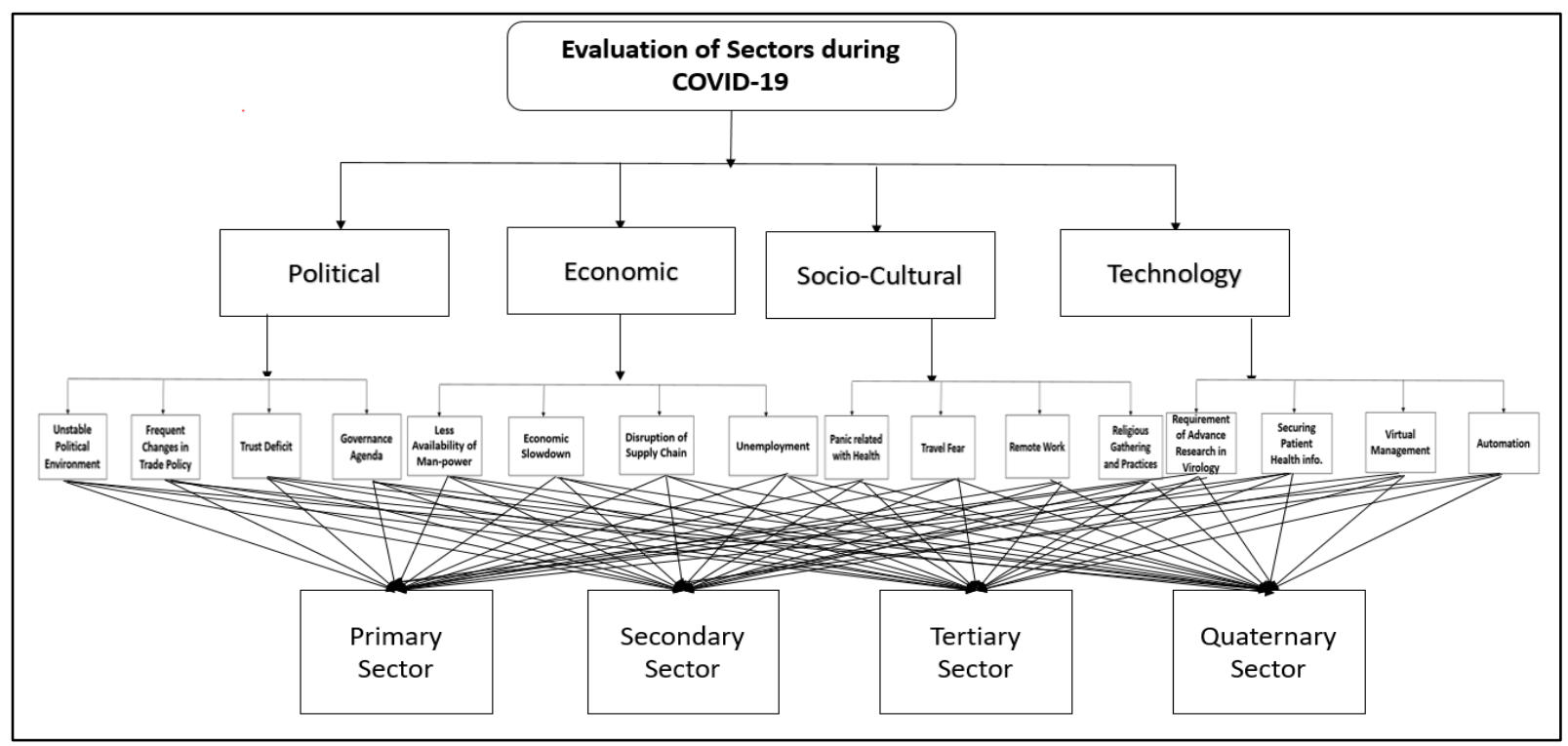

Figure 2: Hierarchical Structure

The abbreviations shown in the above figure are defined below: 
DOI: 10.14807/ijmp.v12i8.1491

Stage 1: The first stage is related to the prioritization of different political, economic, sociocultural and technology consequences affected by COVID-19 pandemic.

Political (P): The COVID-19 pandemic has impacted foreign affairs and the democratic processes of several nations, triggered the disruption of governmental operations, exile or death of several officials, and the postponement of elections owing to concerns of transmission of the virus. (Bol et al. 2020)

Economic (E): The economic crisis caused by the emergence of COVID-19 is affecting countries, irrespective of their amount of wealth. Factories, Hotels, Bars, Stores, Airlines, Shops, Malls, educational institutions etc. have been shut down. The apprehension of coronavirus has restricted the movements of individuals. People weren't just able to afford the basics regularly and influencing the economies of the country as a whole. Economic factors forced the government to remove the tight lockdown even though the dissemination of the Covid-19 had not been controlled (Singh and Neog, 2020)

Socio-Cultural (S): Through the pandemic of COVID-19, individual attitudes are shifting rapidly, with individuals making a plunge into recognizing their most "basic" human needs. COVID-19 has influenced every area of life around the globe, from human partnerships to administrative activities to multinational alliances. Beyond the imminent danger to health, COVID-19 is still squandering the cultural program, prompting the postponement and interruption of some of the most substantial cultural activities (Tomar et al., 2020).

Technology (T): During the COVID-19, technology played a vital role in maintaining our civilization working in a time of lockdown. In this challenging time, it is clear that technologyrelated with artificial intelligence is crucial to helping us cope successfully with this pandemic (Kumar et al., 2020).

Stage 2: The second stage is related to the prioritization of different sub-criteria related to political, economic, socio-cultural and technology (Gunaseelan and Kesavan, 2020; Ritter and Pedersen, 2020; Bartik et al., 2020) consequences affected by COVID-19 pandemic.

Unstable Political Environment (C11): Many of the state governments are already being evaluated for their slow and unconcerned responses to coronavirus outbreaks. This monitoring is likely to have little implications in many of the country's states, however, it may lead to change in others.

Frequent Changes in Trade Policy (C12): Coronavirus can also, for a variety of causes, contribute to changes in trade. For example, as coronavirus begins to cross the globe, several 
DOI: 10.14807/ijmp.v12i8.1491

countries may acknowledge the dependency of their distribution networks on others. Particular production chains that have been affected involve medical-grade face masks; certain countries may choose to continue producing masks domestically in the future in order to be more equipped for potential outbreaks of disease.

Trust Deficit (C13): The trust deficit seems to have now hit its nadir, with the world debating China's involvement in the spread of COVID-19 and it forces India to stop their trade with them.

Governance Agenda (C14): Owing to the COVID-19 pandemic, now could also be the best moment to rethink the government policy discourse and how post-COVID-19 has to be practiced in and around the next few years.

Less Availability of Manpower (C21): When more people get infected, coronavirus is expected to contribute to a possible lack of workforce. If that is related to quarantines or employees choose to live at home, the final outcome remains the same; businesses and authorities will be urged to seek labour. It is expected to contribute to a decline in economic production, as the industry comes to a halt for many.

Economic Slowdown (C22): The economy has been severely impacted by the lockdowns. For many weeks, manufacturing plants, stores and agricultural markets have been shut down, supply chains have been disrupted and transport systems have been discontinued. The economy has already witnessed a slowdown, partly due to the structural crisis.

Disruption of supply chain and global trade (C23): The maximum effect of COVID-19 on supply chains is still uncertain, with the most ambitious projections expecting "normality", however due to lockdown or restrictions in moving is affecting transportation of within the country severely.

Unemployment (C24): A devastating effects on an economy as big as India triggered by a complete lockdown was inevitable. Unemployment could have been the result of a drop in demand and a shift in the workforce experienced by businesses. The truth of the ground might be worse, and impacting the economy.

Panic related with health (C31): Fear of infection or contamination is a significant factor that triggers depression and anxiety in people and has a direct effect on their wellbeing and health. Travel Fear (C32): Coronavirus has now prevented many individuals from travelling. This would come as no shock, considering the danger of being quarantined away from home and 
DOI: 10.14807/ijmp.v12i8.1491

the much higher chance of contracting the infection. Although this is a socio-cultural trend, it has significant economic consequences; travelling firms, for example, are confronted with a severe shortage of passengers and massive losses.

Remote Work (C33): Due to an outbreak of coronavirus, certain people may not be willing to go to work, so individual businesses can prefer to facilitate remote employment, if appropriate to their line of operation. Although this is a short-term adjustment, it may inspire businesses to encourage remote work in the future if the idea continues to be valid.

Religious Gathering and Practices (C34): Restrictions have been implemented at holy places in India and across the globe, in fear of the transmission of the novel coronavirus.

Requirement of Advance Research in Virology (C41): Coronavirus is expected to contribute to various advancements in virology. The existence and propagation of the virus should prove useful to scientists pursuing a deeper understanding of how this pathogen and those like it can be handled and managed.

Securing patient health info (C42): The unexpected socio-cultural effect of the coronavirus outbreak is a disproportionate level of discrimination that happened with the corona infected patients. Since coronavirus was thought have worse influence individuals became prejudiced to infected individuals in their local areas, in fact, this even resulted in some physical assaults.

Virtual Management (C43): The COVID-19 outbreak has speeded up the number of people working virtually in the capacity of an individual or as a team. The management of virtual teams is wholly different from physical work teams. How much employees are engaged during work from home is still a doubt for many.

Automation (C44): Automation is a modern form of technology in which computer systems are used to run various procedures with minimal human assistants. This necessity has only been heightened by the pandemic. The usage of robotics in various sectors as well as in the health sector has also been seen recently.

Stage 3: The third and final stage is related to the prioritization of different economic sectors (Ravallion and Datt, 1996; Sastry et al., 2003; Papola, 2006; Basu and Maertens, 2007) that are affected by COVID-19 pandemic.

Primary Sector (PS): During COVID-19, problems have emerged with respect to logistics, concerning the transport of raw-materials from one location to another. With all agricultural 
DOI: 10.14807/ijmp.v12i8.1491

goods with a limited shelf period, this obstructive aspect of the supply chain has created a great deal of harm not only to the primary sector but also to the whole economy.

Secondary Sector (SS): The secondary sector has been affected in many ways because of the Corona outbreak. Due to disturbances in the timely supply of raw materials, the end consumer often begins postponing non-essential transactions and disengages from processing products by deferring their needs.

Tertiary Sector (TS): The negative effect on the Indian tertiary sector due to COVID-19 pandemic has not yet been fully realized. There is a significant problem for businesses that depend extensively on in-person contact, spanning a wide variety of sectors from finance and banking to retail, hospitality. Effect on these service industries impacting upon the growth rate of the economy.

Quaternary Sector (QS): COVID-19 has severely affected R\&D in pharmaceutical and MedTech sectors. Heads will plan on three horizons- safeguarding staff, enhancing rehabilitation mechanisms, and preparing for the next normal.

\section{RESULTS}

The hierarchical structure of the considered situation has been constructed by using a multiple number of criteria and sub-criteria, as shown in Figure 2. According to the obtained survey result, the criteria and sub-criteria with highest total rank have been used to form the hierarchy table to evaluate the impact of COVID-19 on the different economic sectors of India. A total of four major criteria, each with their own various sub-criteria were chosen for the COVID-19 impact on economic sectors. The main criteria and sub-criteria have been evaluated and have also been compared and the pair-wise comparison matrix has been built and their weights determined by using the AHP have been given in Table 1-5. Consistency test has also been carried and it is found to be below than the desired value.

Table 1: Pair-wise Evaluation of Stage 1 Criteria's

\begin{tabular}{|c|c|c|c|c|c|c|}
\hline & $\mathbf{P}$ & $\mathbf{E}$ & $\mathbf{S}$ & $\mathbf{T}$ & Weight & Rank \\
\hline $\mathbf{P}$ & 1 & 0.375 & 0.750 & 0.429 & 0.136 & 4 \\
\hline $\mathbf{E}$ & 2.667 & 1 & 2 & 1.143 & 0.364 & 1 \\
\hline $\mathbf{S}$ & 1.33 & 0.5 & 1 & 0.571 & 0.182 & 3 \\
\hline $\mathbf{T}$ & 2.33 & 0.875 & 1.750 & 1 & 0.318 & 2 \\
\hline
\end{tabular}

Result of the matrix indicated that the economic consequences have the most significant weightage with 0.516 , and political consequences have the least significant weightage with 0.042 . 
DOI: 10.14807/ijmp.v12i8.1491

Table 2: Pair-wise Evaluation of Political Criteria's

\begin{tabular}{|c|c|c|c|c|c|c|}
\hline & C11 & C12 & C13 & C14 & Weight & Rank \\
\hline C11 & 1 & 0.429 & 0.60 & 0.75 & 0.158 & 4 \\
\hline C12 & 2.33 & 1 & 1.40 & 1.75 & 0.368 & 1 \\
\hline C13 & 1.67 & 0.714 & 1 & 1.25 & 0.263 & 2 \\
\hline C14 & 1.33 & 0.571 & 0.80 & 1 & 0.210 & 3 \\
\hline
\end{tabular}

Result of the matrix indicated that the changes in trade policy have the most significant weightage with 0.368 , and unstable political environment has the least significant weightage with 0.158 in the political factors that are affecting during COVID-19.

Table 3: Pair-wise Evaluation of Economic Criteria's

\begin{tabular}{|l|c|c|c|c|c|c|}
\hline & C11 & C12 & C13 & C14 & Weight & Rank \\
\hline C11 & 1 & 0.625 & 0.833 & 0.714 & 0.192 & 4 \\
\hline C12 & 1.60 & 1 & 1.33 & 1.143 & 0.308 & 1 \\
\hline C13 & 1.20 & 0.75 & 1 & 0.857 & 0.231 & 3 \\
\hline C14 & 1.40 & 0.875 & 1.167 & 1 & 0.269 & 2 \\
\hline
\end{tabular}

Result of the matrix indicated that the economic slowdown has the most significant weightage with 0.308 , and unavailability of man-power has the least significant weightage with 0.192 in the economic factors that are affecting during COVID-19.

Table 4: Pair-wise Evaluation of Socio-cultural Criteria's

\begin{tabular}{|l|c|c|c|c|c|c|}
\hline & C11 & C12 & C13 & C14 & Weight & Rank \\
\hline C11 & 1 & 2 & 1.33 & 2.667 & 0.381 & 1 \\
\hline C12 & 0.50 & 1 & 0.667 & 1.33 & 0.190 & 3 \\
\hline C13 & 0.75 & 1.50 & 1 & 2 & 0.286 & 2 \\
\hline C14 & 0.375 & 0.75 & 0.50 & 1 & 0.142 & 4 \\
\hline
\end{tabular}

Result of the matrix indicated that the panic related with health has the most significant weightage with 0.381 , and religious gathering and practices have the least significant weightage with 0.142 in the economic factors that are affecting during COVID-19.

Table 5: Pair-wise Evaluation of Technology Criteria's

\begin{tabular}{|l|c|c|c|c|c|c|}
\hline & C11 & C12 & C13 & C14 & Weight & Rank \\
\hline C11 & 1 & 1.167 & 0.875 & 1.4 & 0.269 & 2 \\
\hline C12 & 0.857 & 1 & 0.75 & 1.2 & 0.231 & 3 \\
\hline C13 & 1.143 & 1.33 & 1 & 1.6 & 0.308 & 1 \\
\hline C14 & 0.714 & 0.833 & 0.625 & 1 & 0.192 & 4 \\
\hline
\end{tabular}

Result of the matrix indicated that the virtual management have the most significant weightage with 0.308 , and automation has the least significant weightage with 0.192 in the economic factors that are affecting during COVID-19.

All the matrices are found to be consistent, as the value of CR of the comparison matrices is less than 0.1 with the values of $0.004,0.005,0.005,0.003$ and 0.001 respectively. Table 6 shows the final weight of sub-criteria's obtained by multiplying the main criteria with their subsequent sub-criteria weight. 
DOI: 10.14807/ijmp.v12i8.1491

Table 6: Criteria and sub-criteria weight

\begin{tabular}{|c|c|c|c|c|c|c|c|}
\hline Criteria & Weight & $\begin{array}{l}\text { Sub- } \\
\text { criteria }\end{array}$ & Weight & Criteria & Weight & $\begin{array}{l}\text { Sub- } \\
\text { criteria }\end{array}$ & Weight \\
\hline \multirow{4}{*}{$\mathbf{P}$} & \multirow{4}{*}{0.136} & C11 & 0.021 & \multirow{4}{*}{ S } & \multirow{4}{*}{0.182} & C31 & 0.069 \\
\hline & & C12 & 0.050 & & & C32 & 0.035 \\
\hline & & C13 & 0.036 & & & C33 & 0.052 \\
\hline & & C14 & 0.029 & & & C34 & 0.026 \\
\hline \multirow{4}{*}{$\mathbf{E}$} & \multirow{4}{*}{0.364} & C21 & 0.070 & \multirow{4}{*}{$\mathbf{T}$} & \multirow{4}{*}{0.318} & C41 & 0.086 \\
\hline & & C22 & 0.112 & & & C42 & 0.073 \\
\hline & & C23 & 0.084 & & & C43 & 0.098 \\
\hline & & C24 & 0.098 & & & C44 & 0.061 \\
\hline
\end{tabular}

After obtaining the sub-criteria's weight, our next task is to find out the economic sector which are affecting by most during the COVID-19 pandemic. The economic sectors are evaluated based on the score given by the experts and the criteria weights.

Table 7: Criteria and sub-criteria weight

\begin{tabular}{|l|c|c|c|c|}
\hline Sector & $d_{i}^{+}$ & $d_{i}^{-}$ & $R_{i}^{*}$ & Rank \\
\hline Primary & 0.12 & 0.08 & 0.40 & 3 \\
\hline Secondary & 0.04 & 0.18 & 0.82 & 2 \\
\hline Tertiary & 0.03 & 0.18 & 0.90 & 1 \\
\hline Quaternary & 0.19 & 0.03 & 0.14 & 4 \\
\hline
\end{tabular}

Following the steps as given in Section 2, the relative proximity of the considered economic sectors is calculated by Equation (9). It indicates that the tertiary sector is the most affected economic sector, followed by secondary, primary and quaternary sector.

The economic crisis brought by COVID-19 is very distinct from the global economic and financial crises of 2009 in certain critical ways. The first goal is to find a way to kill or neutralize the symptoms of the virus. Then all such economy boost related fights will be waged after we have passed this specific hurdle. However, the ongoing recession is a result of supplyside problems and a fall in production. When production is enhanced by the stimulus, supplyside fluctuations will have to be removed concurrently so that both sides can emerge together from the crisis. Undoubtedly, the pandemic trigger systemic changes in the Indian economic environment, but it will entail an effective and efficient strategy and tactical policies, not slogans.

\section{CONCLUSION}

In this study, we examined the problem of COVID-19 impact on the different economic sectors of India through a multiple attribute decision making approach by using the AHP and TOPSIS technique. This paper proposed a hierarchical model consisting of four main criteria's with 16 sub-criteria. The results of the study have shown that the tertiary sector is the most affected economic sector with the highest relative proximity of 0.90 than any other economic 
DOI: 10.14807/ijmp.v12i8.1491

sectors. The findings are obtained only by employing a hybrid MCDM technique. In future studies relevant to the same problem, several other requirements can also be considered and various statistical methodological approaches can also be used in future research to verify the findings.

\section{REFERENCES}

Babu, K. A., \& Venkataramaiah, P. (2015). Multi-response optimization in wire electrical discharge machining (WEDM) of Al6061/SiCp composite using hybrid approach. Journal for Manufacturing Science and Production, 15(4), 327-338. DOI: https://doi.org/10.1515/jmsp-2015-0010

Balajee, A., Tomar, S., \& Udupa, G. (2020). Fiscal Situation of India in the Time of COVID19. Indian School of Business. DOI: http://dx.doi.org/10.2139/ssrn.3571103

Bartik, A. W., Bertrand, M., Cullen, Z., Glaeser, E. L., Luca, M., \& Stanton, C. (2020). The impact of COVID-19 on small business outcomes and expectations. Proceedings of the National Academy of Sciences, 117(30), 17656-17666.

DOI: https://doi.org/10.1073/pnas.2006991117

Basu, K., \& Maertens, A. (2007). The pattern and causes of economic growth in India. Oxford Review of Economic Policy, 23(2), 143-167. DOI:

https://doi.org/10.1093/oxrep/grm012

Bol, D., Giani, M., Blais, A., \& Loewen, P. J. (2020). The effect of COVID-19 lockdowns on political support: Some good news for democracy?. European Journal of Political Research. DOI: https://doi.org/10.1111/1475-6765.12401.

Buheji, M., Da Costa Cunha, K., Beka, G., Mavric, B., De Souza, Y. L., Da Costa Silva, S. S., \& Yein, T. C. (2020). The extent of covid-19 pandemic socio-economic impact on global poverty. A global integrative multidisciplinary review. American Journal of Economics, 10(4), 213-224. DOI: 10.5923/j.economics.20201004.02

Deshmukh, S. G., \& Haleem, A. (2020). Framework for Manufacturing in Post-Covid-19 World Order: An Indian Perspective. International Journal of Global Business and Competitiveness. DOI: https://doi.org/10.1007/s42943-020-00009-1

Dev, S. M. (2020). Addressing COVID-19 impacts on agriculture, food security, and livelihoods in India. IFPRI book chapters, 33-35. Available: https://www.ifpri.org/cdmref/p15738coll2/id/133824/filename/134027.pdf Access: 25th October, 2020.

Dev, S. M., \& Sengupta, R. (2020). Covid-19: Impact on the Indian economy. Indira Gandhi Institute of Development Research, Mumbai April. Available: http://www.igidr.ac.in/pdf/publication/WP-2020-013.pdf Access: 25th October, 2020.

Dwivedi, G., Srivastava, R. K., \& Srivastava, S. K. (2018). A generalised fuzzy TOPSIS with improved closeness coefficient. Expert Systems with Applications, 96, 185-195. DOI: https://doi.org/10.1016/j.eswa.2017.11.051

Gopalan, H. S., \& Misra, A. (2020).. COVID-19 Pandemic and Challenges for Socioeconomic Issues, Healthcare and National Programs in India. Diabetes \& Metabolic Syndrome: Clinical Research \& Reviews. DOI: https://doi.org/10.1016/j.ajp.2020.102254 
Gunaseelan, S., \& Kesavan, N. (2020). Business and economic recessions in india during the covid-19-a review. Journal of Xi'an University of Architecture \& Technology, 12.

Available: http://www.xajzkjdx.cn/gallery/32-april2020.pdf Access: 25th October, 2020.

Hwang, C. L., Lai, Y. J., \& Liu, T. Y. (1993). A new approach for multiple objective decision making. Computers and Operational Research, 20(8), 889-899. DOI: https://doi.org/10.1016/0305-0548(93).90109-V

Kumar, A., Gupta, P. K., \& Srivastava, A. (2020). A review of modern technologies for tackling COVID-19 pandemic. Diabetes \& Metabolic Syndrome: Clinical Research \& Reviews. DOI: https://doi.org/10.1016/j.dsx.2020.05.008

Papola, T. S. (2006). Emerging structure of Indian economy: Implications of growing intersectoral imbalances. The Indian Economic Journal, 54(1), 5-25. DOI:

https://doi.org/10.1177/0019466220060102

Ravallion, M., \& Datt, G. (1996). How important to India's poor is the sectoral composition of economic growth?. The World Bank Economic Review, 10(1), 1-25. DOI:

https://doi.org/10.1093/wber/10.1.1

Reardon, T., Mishra, A., Nuthalapati, C. S., Bellemare, M. F., \& Zilberman, D. (2020). Covid-19's disruption of india's transformed food supply chains. Economic and Political Weekly, 55(18),18-22. Available:https:/www.epw.in/journal/2020/18/commentary/covid19sdisruption-indias-transformed-food.html Access: 25th October, 2020.

Ritter, T., \&Pedersen, C. L. (2020). Analyzing the impact of the coronavirus crisis on business models. Industrial Marketing Management. DOI:

https://doi.org/10.1016/j.indmarman.2020.05.014

Saaty, T. L. (1989). Group decision making and the AHP. In The analytic hierarchy process Springer, Berlin, Heidelberg, p 59-67. DOI: https://doi.org/10.1007/978-3-64250244-6_4

Sastry, D. V. S., Singh, B., Bhattacharya, K., \& Unnikrishnan, N. K. (2003). Sectoral linkages and growth prospects: Reflections on the Indian economy. Economic and Political Weekly, 2390-2397. Available: https://www.jstor.org/stable/4413682?seq=1 Access: 25th October, 2020.

Sengupta, S., \& Jha, M. K. (2020). Social policy, COVID-19 and impoverished migrants: challenges and prospects in locked down India. The International Journal of Community and Social Development. DOI: https://doi.org/10.1177/2516602620933715

Sharma, G. D., Talan, G., \& Jain, M. (2020a).. Policy response to the economic challenge from COVID-19 in India: A qualitative enquiry. Journal of Public Affairs, 2206. DOI: https://doi.org/10.1002/pa.2206

Sharma, G. D., Talan, G., Srivastava, M., Yadav, A., \& Chopra, R. (2020b). A qualitative enquiry into strategic and operational responses to Covid-19 challenges in South Asia. Journal of Public Affairs, 2195. DOI: https://doi.org/10.1002/pa.2195

Singh, M. K., \& Neog, Y. (2020). Contagion effect of COVID-19 outbreak: Another recipe for disaster on Indian economy. Journal of Public Affairs, 2171. DOI:

https://doi.org/10.1002/pa.2171

Tomar, B. S., Singh, P., Nathiya, D., Suman, S., Raj, P., Tripathi, S., \& Chauhan, D. S. (2020). Indian community's Knowledge, Attitude \& Practice towards COVID-19. medRxiv. DOI: https://doi.org/10.1101/2020.05.05.20092122 
ISSN: 2236-269X

DOI: 10.14807/ijmp.v12i8.1491

Verma, S., Saharan, A., Polcumpally, A. T., \& Biswas, M. (2020). Tentacles of COVID-19 in India: Impact on Indian Economy, Society, Polity and Geopolitics. Journal of Humanities and Social Science Studies, 2(3), 54-61. Available:

http://dspace.jgu.edu.in:8080/jspui/handle/10739/3939 Access: 25th October, 2020.

Wu, C. R., Chang, H. Y., \& Wu, L. S. (2009). Evaluating optimal choice of the energy fund by using AHP-TOPSIS model. Journal of Information and Optimization Sciences, 30(6), 1081-1098. DOI: https://doi.org/10.1080/02522667.2009.10699929 